\title{
Acquired epidermodysplasia verruciformis in a renal transplant recipient - Case report
}

\author{
Alena Darwich Mendes ${ }^{1}$ \\ Emanuella Rosyane Duarte Moure ${ }^{3}$ \\ Igor Nagai Yamaki ${ }^{4}$
}

\author{
Maraya de Jesus Semblano Bittencourt ${ }^{2}$ \\ Camila Maria D'Macêdo ${ }^{4}$ \\ Dyandra Moreira de Araújo ${ }^{4}$
}

DOI: http://dx.doi.org/10.1590/abd1806-4841.20142803

\begin{abstract}
A 24-year-old male patient, who underwent kidney transplant six years ago due to Lupus nephritis, for the last two years presented asymptomatic erythematous scaly plaques on the abdomen and areas exposed to light. Post-transplantation immunosuppressive medications included prednisone, mycophenolate sodium and sirolimus. The histopathologic features were typical for epidermodysplasia verruciformis. Epidermodysplasia verruciformis is a rare autosomal recessive genodermatosis with increased susceptibility to specific strains of cutaneous human papilloma virus. The term "acquired epidermodysplasia verruciformis" was recently introduced to the literature and describes epidermodysplasia verruciformis occurring in patients with impaired cell-mediated immunity. We report an additional case associated to immunosuppression after kidney transplantation.
\end{abstract}

Keywords: Epidermodysplasia verruciformis; Immunosuppression; Kidney transplantation

\section{INTRODUCTION}

Epidermodysplasia verruciformis (EV), initially described by Lewandowski and Lutz in 1922, is a rare genodermatosis, autosomal recessive or linked to the $\mathrm{X}$ chromosome, characterized by susceptibility to chronic infection and disseminated by specific strains of human papilloma virus (HPV), secondary to defect in cellular immunity. Its onset is usually in early childhood, with the appearance of hypo or hyperpigmented macules, pityriasis versicolor-like lesions, flat warts and early development of skin carcinomas., ${ }^{1,2}$ There are at least 20 types of HPVs associated with EV, which include types $3,5,8,9,10,12,14,15,17,19-25,38,29,36,46,47,49$ and $50 .^{3}$ These viruses have oncogenic potential in these patients and around 30 to $60 \%$ of affected patients may develop squamous cell carcinoma, usually in areas exposed to sunlight and in the fourth decade of life. ${ }^{3}$ The term acquired EV was recently introduced in the literature to describe EV developing in the immunocompromised host, like carriers of acquired immunodeficiency virus, Hodgkin disease and systemic lupus erythematosus. ${ }^{3-6}$ Reports of acquired EV in kidney transplanted patients are rare, with few cases described in the worldwide literature to date. ${ }^{7-9}$

\section{CASE REPORT}

A 24-year-old male patient, student, presented for two years asymptomatic lesions in areas exposed to light, which increased progressively in number. He used oral and topical antifungals without improvement. He had history of systemic lupus erythematosus for 11 years and kidney transplant due to renal failure secondary to lupus nephritis for the last 6 years and, for this reason, he is undergoing immunosuppressant treatment with sirolimus $1 \mathrm{mg} 2 \mathrm{x} /$ day, mycophenolate sodium $360 \mathrm{mg} /$ day and prednisone $10 \mathrm{mg} /$ day. There was no history of consanguinity and affected relatives. On examination, he had numerous erythematous papules and macules (pityriasis versicolor-like) on his face, neck, V-shaped neckline, forearms and abdomen (Figure 1). Histologic examination of the skin biopsy from abdomen revealed vacuolated cells in the upper epidermis with a bubbly, bluish cytoplasm, thickened granular layer and mild perivascular infiltrate in the superficial dermis, consistent with EV (Figure 2).

Approved by the Advisory Board and accepted for publication on 01.07.2013.

* Work performed at the Dermatology Service of the University Center of the State of Pará (Centro Universitário do Estado do Pará - CESUPA) - Belém (PA), Brazil. Conflict of interest: None

Financial funding: None

MD, Master's degree in Dermatology from Universidade do Estado do Rio de Janeiro (UERJ) - Assistant Professor of Dermatology at Universidade do Estado do Pará (UEPA) and Head of the Dermatology Service at Centro Universitário do Estado do Pará (CESUPA) - Belém (PA), Brazil.

MD, Master's degree in Tropical Diseases - Assistant professor of Dermatology at Universidade Federal do Pará (UFPA) and Internship professor of Dermatology at Centro Universitário do Estado do Pará (CESUPA) - Belém (PA), Brazil.

MD, Master's degree in hair and nails from Universidade de São Paulo (USP) - Professor of Dermatology at Centro Universitário do Estado do Pará (CESUPA) - Belém (PA). Brazil

Undergraduate medical student at Centro Universitário do Estado do Pará (CESUPA) - Belém (PA). Brazil 

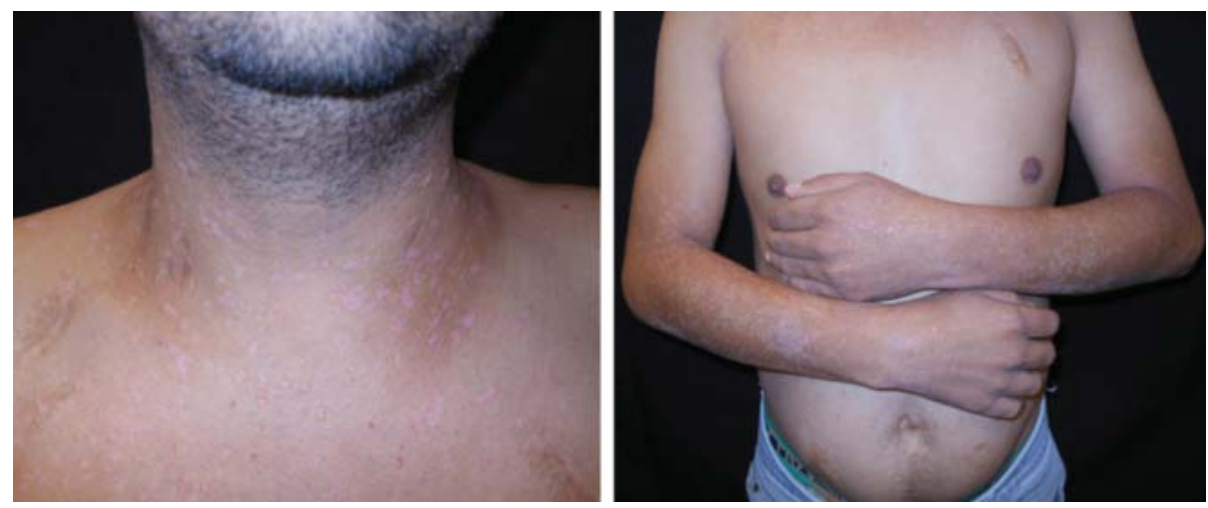

Figure 1:

Erythematous papules, pityriasis versicolor-like plaques, on areas exposed to light

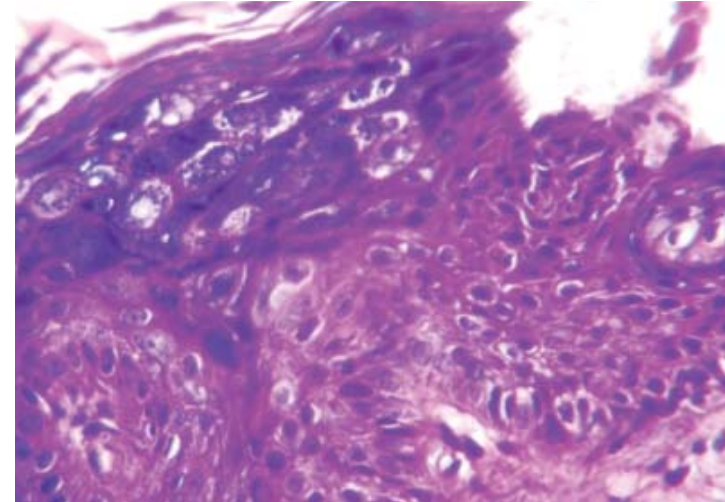

FIGURE 2: A biopsy from the abdomen shows bubbly bluish cytoplasm and thickened granular layer consistent with epidermodysplasia verruciformis

\section{DISCUSSION}

The pathogenesis of congenital EV remains unknown. On familial cases were found mutations of EVER1/TMC6 and EVER2/TMC8 genes, present in chromosome $17 q 25$. These mutations could negatively regulate cell-mediated immunity, by diminishing the capability of presenting peptides derived from HPV to T lymphocytes. Immunosuppressed patients acquire susceptibility to HPV that cause EV, innocuous to the general population, highlighting the role of cell-mediated immunity in resistance to the HPVs that cause the syndrome. Similar to inherited EV, HPVs 5 and 8 are the most common subtypes found in acquired EV. ${ }^{3}$ Although these are associated with the development of squamous cell carcinoma in inherited $\mathrm{EV}$, the potential for malignancy in acquired forms is uncertain. ${ }^{3}$ Our patient was on immunosuppressing treatment with sirolimus, prednisone and mycophenolate sodium. Sirolimus acts on cell immunity by $\mathrm{T}$ lymphocytes activation and proliferation inhibition. On cells, sirolimus links itself to immunophilin, binding protein FK 12 (FKBP-12), in order to form an immunosuppressant complex. The sirolimus/FKBP12 complex does not have effects over calcineurin activity. This complex links itself to mTOR, an important regulatory kinase, inhibiting its activity. This inhibition suppresses cytokine-induced $\mathrm{T}$ cell proliferation, inhibiting the progression of phase $G_{1}$ to phase $S$ of the cell cycle. ${ }^{10}$ Mycophenolate sodium is a competitive and reversible inhibitor of inosine monophosphate dehydrogenase and, therefore, inhibits the de novo synthesis of guanosine nucleotides, with no DNA incorporation. Mycophenolate sodium has potent cytostatic effects over lymphocytes, since $\mathrm{B}$ and $\mathrm{T}$ lymphocytes are critically dependent on purines for their proliferation, whereas other types of cells can use alternative pathways. Prednisone acts on growth, differentiation and maturation of the lymphocyte, inhibiting proliferation of germinal centers of lymph nodes and spleen. The clinical and histopathological manifestations of EV are similar in the two clinical forms. The histopathological exam of lesions shows hyperkeratosis, acanthosis, keratinocytes with ample cytoplasm and picnotic nuclei, located in the granular layer. The main objective of EV treatment is to avoid the malignant transformation of lesions, for up to this moment there is no effective therapy for the congenital and acquired forms. The use of sunscreen is recommended for all patients at the time of diagnosis. Among the therapeutic options are topical and systemic retinoids with antiproliferative action, imiquimod, cryotherapy, 5-fluorouracil and topical cidofovir, none of them with proven effectiveness. ${ }^{1}$ Interferon can be utilized due to its antiviral action mechanism, besides stimulating T cells. With prolonged life expectancy of immunosuppressed patients it is fundamental that patients undergo complete dermatological exams periodically, to detect skin alterations resulting from cell immunity defects, among which EV stands out due to probable risk of carcinoma development. $\square$ 


\section{REFERENCES}

1. Sá NB, Guerini MB, Barbato MT, Giunta G, Nunes DH. Epidermodysplasia verruciformis: clinical presentation with varied forms of lesions. An Bras Dermatol. 2011;86:S57-60

2. Oliveira WRP, Neto CF, Tyring SK. Clinical aspects of epidermodysplasia verruciformis. An Bras Dermatol. 2002;77:545-6.

3. Rogers HD, Macgregor JL, Nord KM, Tyring S, Rady P, Engler DE, et al. Acquired epidermodysplasia verruciformis. J Am Acad Dermatol. 2009;60:315-20.

4. Berger TG, Sawchuk WS, Leonardi C, Langenberg A, Tappero J, Leboit PE. Epidermodysplasia verruciformis associated papillomavirus infection complicating human immunodeficiency virus disease. Br J Dermatol. 1991;124:79-83.

5. Gross G, Ellinger K, Roussaki A, Fuchs PG, Peter HH, Pfister H. Epidermodysplasia verruciformis in a patient with Hodgkin's disease: characterization of a new papillomavirus type and interferon treatment. J Invest Dermatol. 1988;91:43-8.

6. García-Río I, Garcia-F-Villalta MJ, Daudén E, Fraga J, García-Díez A. Epidermodysplasia Verruciformis-like Lesions in a Patient with Systemic Lupus Erythematosus. Acta Derm Venereol. 2003;83:229-30.

7. Lutzner M, Croissant 0 , Ducasse MF, Kreis H, Crosnier J, Orth G. A potentially oncogenic human papillomavirus (HPV5) found in two renal allograft recipients. $J$ Invest Dermatol. 1980;75:353-6.

8. Lutzner MA, Orth G, Dutronquay V, Ducasse MF, Kreis H, Crosnier J. Detection of human papillomavirus type 5 DNA in skin cancers of an immunosuppressed renal allograft recipient. Lancet. 1983;2:422-4.

9. Gómez-Bernal S, Rodríguez-Pazos L, Pereiro-Ferreirós MM, Toribio J. Acquired epidermodysplasia verruciformis in a renal transplant recipient. Actas Dermosifiliogr. 2011;102:159-61

10. Campistol JM, Grinyó JM. Exploring treatment options in renal transplantation: The problems of chronic allograft dysfunction and drug-related nephrotoxicity. Transplantation. 2001;71:SS42-51.

\author{
MAILING ADDRESS: \\ Maraya de Jesus Semblano Bittencourt \\ Avenida Almirante Barroso, 3775 \\ 66.613-903 - Belém - PA \\ Brazil \\ E-mail:marayabittencourt@hotmail.com
}

How to cite this article: Mendes AD, Bittencourt MJS, Moure ERD, D'Macêdo CM, Yamaki IN, Araújo DM. Acquired epidermodysplasia verruciformis in a renal transplant recipient: case report. An Bras Dermatol. 2014;89(1)144-6. 